\title{
Sperm transport in the reproductive tract of female zebra finches (Taeniopygia guttata)
}

\author{
T. R. Birkhead and F. Fletcher \\ Department of Animal and Plant Sciences, The Unizersity of Sheffield, Sheffield S10 2TN, UK
}

\begin{abstract}
Aspects of sperm transport in the oviducts of female zebra finches were examined by recording the decline in the number of spermatozoa on the outer perivitelline layer of successively laid eggs. Data from a single clutch of eggs from 32 females indicates that the mean per capita rate of loss of spermatozoa was estimated to be $0.0170 \pm 0.002 \mathrm{SEM}$ spermatozoa $\mathrm{h}^{-1}$. However, individual females showed no consistency in the rate at which spermatozoa were lost from their oviduct over five successive clutches. Models of the mechanism of sperm competition in birds assume that the rate of loss of spermatozoa does not differ between inseminations made before or after the start of egg laying. This assumption was found to be valid: the instantaneous per capita rate of loss of spermatozoa did not differ significantly between females inseminated either before $\left(0.01445 \pm 0.0028\right.$ SEM spermatozoa $\left.\mathrm{h}^{-1}\right)$ or after $\left(0.01674 \pm 0.0023\right.$ SEM spermatozoa $\left.\mathrm{h}^{-1}\right)$ the onset of oviposition. The rate of sperm transport through the infundibulum was determined to be slower than that between the utero-vaginal sperm storage tubules and the infundibulum by comparing the number of spermatozoa associated with the perivitelline layers of eggs laid after a day on which no eggs were laid. Eggs with $<20$ spermatozoa on the outer perivitelline layer were found to have a $50 \%$ probability of being infertile. The results are compared with data for domestic fowl and turkeys.
\end{abstract}

\section{Introduction}

In most species with internal fertilization there is a massive reduction in the number of spermatozoa as they are transported between the site of insemination and the point of fertilization. Neither the mechanisms nor the functional significance of this reduction are well understood (Bedford, 1970; Suarez et al., 1990; Birkhead ot al., 1993a). The points in the female reproductive tract at which numbers of spermatozoa are reduced are reasonably well known in certain mammals and birds (Drobnis and Overstreet, 1992; Bakst of al., 1994), but it is not known whether this reduction constitutes the non-random selection of spermatozoa. Information on sperm transport and use in birds has been derived mainly from non-passerines, such as domestic fowl, Gallus domesticus, and turkeys, Meleagris gallopawo (Bakst $e$ f al., 1994); much less information is available for passerine birds.

Many reproductive biologists assume that usually spermatozoa from a single male are present in the female tract or interact with a female's ova around the time of fertilization. However, this is unrealistic because females of many animal species typically copulate with several males during each reproductive cycle. The consequence of this is referred to as sperm competition, which is widespread across the animal kingdom (Smith, 1984; Birkhead and Møller,

Received 22 December 1997
1998). Therefore, many reproductive features, including sperm transport in the female tract, are likely to have evolved to some extent in response to sperm competition. An understanding of the way spermatozoa are transported and used in the female tract may help to elucidate the mechanisms of sperm competition and the factors that determine fertilization success when a female is inseminated by more than one male (Parker, 1970; Birkhead and Parker, 1997). Sperm competition is particularly common in passerine birds, which despite being socially monogamous, regularly engage in extra-pair copulations and exhibit high levels of extra-pair paternity (Birkhead and Møller, 1992, 1996).

Birds provide a unique opportunity for examining sperm transport in a non-invasive manner by counting spermatozoa associated with the perivitelline layers of laid eggs. Around the time of fertilization several spermatozoa typically penetrate the inner perivitelline layer, before one fuses with the female pronucleus (Bakst and Howarth, 1977). Within a few minutes of fertilization the outer perivitelline layer is laid down around the ovum, trapping any spermatozoa in the infundibulum and upper oviduct (Bobr et al., 1964; Wishart, 1987). Spermatozoa trapped in the outer perivitelline layer and holes in the inner perivitelline layer can be visualized and counted relatively easily (Wishart, 1987; Steele it al., 1994). The number of spermatozoa and holes associated with perivitelline layers correlate closely with both the numbers of spermatozoa inseminated and those subsequently found in the sperm storage tubules 
(Wishart, 1987; Brillard and Antoine, 1990; Brillard and Bakst, 1990; Brillard, 1993; Wishart, 1995). Moreover, the decline in the number of spermatozoa and holes on successive eggs, after either a single insemination or the cessation of copulation, reflects the efflux of spermatozoa from the sperm storage tubules and transport to the infundibulum (Wishart, 1987).

Estimates of the rate of loss of spermatozoa from the female reproductive tract in birds have been derived largely from poultry and for practical reasons almost entirely from birds inseminated after the onset of egg laying (Wishart, 1987; Brillard and Antoine, 1990; Brillard and Bakst, 1990). In wild birds, copulations always start several days before the onset of oviposition and are most frequent in the days immediately before laying (Birkhead et al., 1987). However, in some species extra-pair copulations may occur during the egg-laying period (Birkhead and Møller, 1992). Determination of whether the rate of loss of spermatozoa differs between inseminations made before or after the onset of egg laying is important in understanding sperm competition, that is, the factors that determine which of two males will fertilize a female's ova (Birkhead et al., 1995; Colegrave ot al., 1995; Birkhead and Biggins, 1998).

The aim of the present study was to examine aspects of sperm use and transport in a passerine bird, the zebra finch, Taeniopygia guttata, using counts of spermatozoa on the perivitelline layers of successive eggs. Specifically, the objectives were: (i) to determine whether the rate of loss of spermatozoa from the oviduct showed any consistency within individual females; (ii) to determine the rate of loss of spermatozoa after inseminations made before or after the start of egg laying; and (c) to determine whether spermatozoa accumulate in the infundibulum.

\section{Materials and Methods}

\section{Animals}

The zebra finch is a small (12-18 g) passerine bird native to Australia and the Lesser Sunda Islands, where it breeds opportunistically and colonially (Zann, 1996). Females typically copulate about 12-15 times in the 5 days before the onset of laying. Clutches comprise five or six eggs which are usually laid at the rate of one egg per day in the early morning. Behavioural and physiological aspects of sperm competition and the reproductive biology of zebra finches in the wild and in captivity have been studied in detail (Birkhead et al., 1989, 1995; Birkhead, 1996). The present study was conducted on captive domesticated zebra finches from an outbred breeding colony established at the University of Sheffield in 1985. The birds were provided with food and water ad libitum and maintained in a $14 \mathrm{~h}$ light: $10 \mathrm{~h}$ dark photoperiod at $20^{\circ} \mathrm{C}$ as described by Birkhead et al. (1989).

\section{Female effects on rate of loss of spermatozon}

The rate at which spermatozoa are lost from the female tract after insemination was estimated using the method described by Wishart (1987). This involved counting the spermatozoa trapped on the outer pervitelline layer of successive eggs after staining the nuclei with fluorescent Hoescht dye 33342 (Sigma, Poole). The number of spermatozoa on successive eggs follows a logarithmic decline indicating the rate of loss from the sperm storage tubules is constant (Wishart, 1987). The slope of the relationship between $\log _{e}$ (number of spermatozoa) and time (h) (eggs are usually laid on consecutive days) provides an estimate of the per capita rate of loss of spermatozoa (see Lessells and Birkhead, 1990; Birkhead, et al., 1993b). Seven females were each paired to a male and were allowed to perform natural copulations until the first egg of a clutch was laid (day 0). Thereafter, pair members were separated with a wire mesh divider to prevent further copulations. All subsequent eggs were removed on the day they were laid to encourage females to continue laying supernormal clutches as has been reported in other studies (Haywood, 1993). Each female produced five successive clutches. The per capita rate of loss of spermatozoa for the five clutches from each female paired to the same male for each mating was then calculated.

Data from this part of the study were also used to establish the relationship between the number of spermatozoa trapped on the outer perivitelline layer and the probability of an egg being fertile. Each egg $(n=129)$ was opened and the appearance of the germinal disc was observed to determine fertility using the same criteria at Kosin (1945). The removal of eggs as they were laid resulted in some females laying greater numbers (up to ten) than the normal clutch of about six eggs. Consequently, some of the eggs laid late in a sequence were found to be infertile, which allowed the number of spermatozoa associated with fertile and infertile eggs to be determined.

\section{Timing of inseminations and loss of spermatozoa}

Ten female zebra finches were allowed to perform a single copulation with a rested male $2-5$ days before the first egg was laid (mean: day $-3.90 \pm 0.348$ SEM) or on day 0 (the day the first egg was laid) to determine whether the timing of insemination relative to the start of oviposition affected the subsequent rate of loss of spermatozoa. The timing of insemination was regulated by keeping each male and female in the same cage but separated by a wire divider and allowing them access to copulate only on certain days. Rested male zebra finches (that is, males that have not copulated in the previous 7 days) ejaculate $8-10 \times 10^{6}$ spermatozoa (Birkhead of al., 1995). The number of spermatozoa on the outer pervitelline layer of successive eggs was recorded and the slope of the relationship between

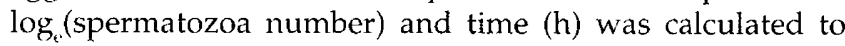
estimate the per capita rate of loss of spermatozoa for each clutch. In females inseminated after the onset of egg laying, spermatozoa were found on the perivitelline layers from the second or third egg laid onwards because copulation occurred on the day the first egg was laid. Only these and subsequent eggs were used in the analyses. 


\section{Sperm transport through the infundibulum}

Spermatozoa that are not involved in fertilization or trapped in the perivitelline layers eventually pass through the infundibulum into the body cavity where they are phagocytosed (Brillard, 1990). The hypothesis that the rate at which spermatozoa pass through the infundibulum into the body cavity is slower than the rate at which spermatozoa pass from the sperm store tubules to the infundibulum was tested. The number of spermatozoa on eggs after a natural 1 day interval in laying was recorded using data from the first part of this study. It was predicted that if spermatozoa accumulate in the infundibulum, the number of spermatozoa on eggs after a 1 day interval in laying should be higher than expected from the decline in numbers on successive eggs.

\section{Statistical analysis}

All statistical tests were two-tailed, unless otherwise stated. Means are presented \pm SEM.

\section{Results}

\section{Feinale effects on rate of loss of spermatozoa}

There was no evidence of consistency in the rate at which spermatozoa were lost from the reproductive tract of individual females. The instantaneous per capita rates of loss of spermatozoa for seven females were: (1) $0.0207 \pm 0.0032$, (2) $0.0129 \pm 0.0036$, (3) $0.0125 \pm 0.003$, (4) $0.0216 \pm 0.009$, (5) $0.0129 \pm 0.002$, (6) $0.0177 \pm 0.0026$, and (7) $0.0208 \pm 0.0034$. An analysis of variance revealed no significant differences between females $\left(F_{6.28}=0.870, P=0.526\right)$, and hence no significant repeatability (Lessells and Boag, 1987) within females (repeatability $=-2.6 \%$ ). The mean instantaneous per capita rate of loss using mean values from each of the 11

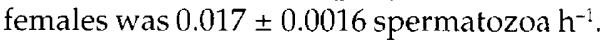

The minimum number of spermatozoa on the outer perivitelline layer of a fertile egg was 11 and the minimum number on an infertile egg was 56 . The presence of fewer than about 20 spermatozoa on the perivitelline layers of eggs resulted in a $50 \%$ probability of fertility (Fig. 1).

\section{Timing of inseminations and loss of spermatozoa}

Females inseminated before laying produced a mean clutch of 4.60 eggs \pm 0.34 (range 3-7) and those inseminated after laying a mean clutch of 5.20 eggs \pm 0.57 (range 4-10). For each bird the regression between $\log _{\mathrm{e}}$ (number of spermatozoa) and time (h) after insemination was calculated and the mean slope and intercept for those birds inseminated before or after the onset of egg laying were compared. The mean slope for females inseminated before laying $(0.01445 \pm$ 0.0028 ) did not differ significantly from that of females inseminated after laying had commenced $(0.01674 \pm 0.0023$, $t=0.632,18$ degrees of freedom (df), $P>0.1)$. Similarly, the intercepts did not differ between birds inseminated before

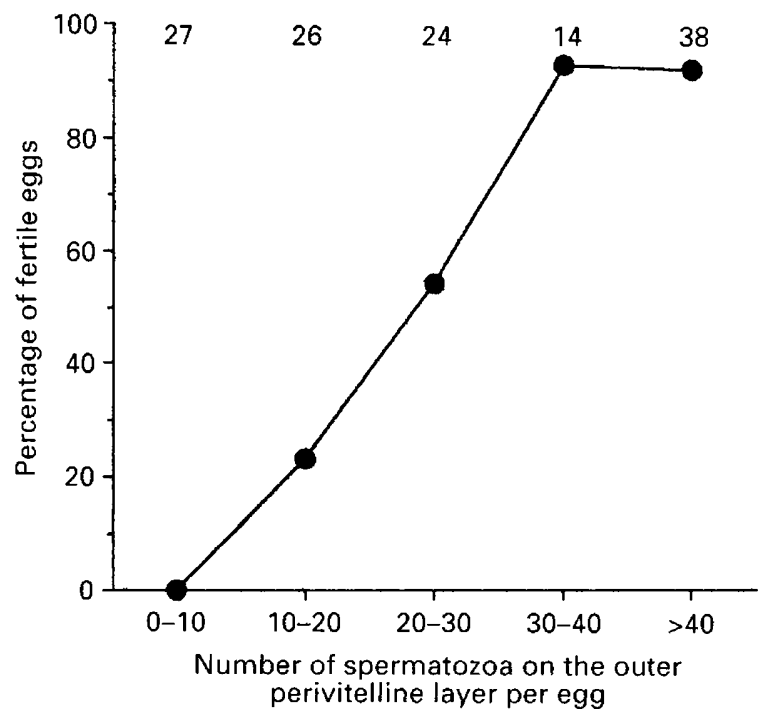

Fig. 1. Relationship between the number of spermatozoa on the outer perivitelline layer of zebra finch eggs and the proportion of fertile eggs. The values at the top of the figure are the numbers of eggs used to calculate the percentage of fertile eggs.

laying (4.9898 \pm 0.648$)$ and those inseminated after laying had started $(5.3109 \pm 0.252 ; t=0.462,18 \mathrm{df}, P>0.1)$. These results are consistent with the hypothesis that the rate of loss of spermatozoa does not differ between the two time periods.

The data on laying of the first egg were analysed to determine whether the absence of a difference in the slopes and intercepts was due to variation in the estimates. This analysis predicts that if the rate of loss is the same before and after the onset of laying, for females inseminated on day 0 the intercept will be significantly greater than for those inseminated before the onset of laying. This is because the time period before the next egg is laid is shorter in females inseminated on day 0 and hence there is less time in which spermatozoa are lost from the female tract. This analysis also predicts that the slope of the relationships for the two time periods will not differ significantly. The results were in agreement with the predicted outcomes. The intercepts differed significantly between birds inseminated before $(3.936 \pm 0.478)$ and after laying $(5.5798 \pm 0.223 ; t=3.10,18 \mathrm{df}$, $P<0.007$ ), whereas the slopes did not differ between birds inseminated before $(-0.0144 \pm 0.003)$ and after laying $\langle 0.01612 \pm 0.002 ; t=0.44,18 \mathrm{df}, P>0.1)$. The overall mean instantaneous per capita rate of loss using these data was $0.0156 \pm 0.002$ spermatozoa $^{-1}(n=20$ females $)$.

\section{Sperm transport through the infundibulum}

In ten clutches (involving ten different pairs of birds) a natural interval of 1 day occurred in a run of consecutive eggs. In five of these ten clutches the number of spermatozoa on the egg after the 1 day interval was higher than for the egg before the interval. In addition, in none of the ten clutches did the number of spermatozoa show an increase on the egg immediately preceding the interval compared with the previous egg. This difference is significant (Fisher's exact 
test, one-tailed, $P=0.032$ ). The increase in spermatozoa on eggs after a 1 day interval in laying was compared with that predicted from the slope of the relationship between number of spermatozoa and time, using data oniy up to the 1 day interval. In each of six cases the observed value (mean $\log _{\mathrm{e}}$ (number of spermatozoa): $3.211 \pm 0.251$ ) was higher than the predicted value $(1.177 \pm 0.363$; paired $t$ test, $t=6.205,5 \mathrm{df}$, $P<0.002)$ confirming that accumulation of spermatozoa occurs in the infundibulum.

\section{Discussion}

The main findings were: (i) there was no consistency in the rate of loss of spermatozoa from the reproductive tract in females, which shows that the variability in this parameter within females is similar to that between females; (ii) the rate of loss of spermatozoa from the female tract did not differ according to whether insemination occurred before or after the onset of oviposition; (iii) $>20$ spermatozoa on the perivitelline layer were required for an egg to have a $>50 \%$ probability of being fertile; and (iv) eggs laid after a 1 day interval in laying had greater numbers of spermatozoa on the perivitelline layers than expected, suggesting accumulation of spermatozoa in the infundibulum.

The ova of birds (and reptiles), unlike those of mammals, are yolky and relatively large. The number of spermatozoa associated with the perivitelline layers of avian ova relates positively and allometrically with ovum size across bird species (Birkhead et al., 1994). This is presumably because on larger ova the germinal disc, that is, the site of the female pronucleus, is a relatively small target and hence disproportionately more spermatozoa are necessary to ensure fertilization (Birkhead et al., 1994). Therefore, the minimum number of spermatozoa to ensure fertilization, or more specifically the number of spermatozoa at which $50 \%$ of eggs fail to be fertilized, would be expected to be relatively lower for the eggs of smaller species. This hypothesis was tested by comparing the data from the present study with data from domestic fowl, the only other bird species in which this type of investigation has been conducted. Wishart (1987) found that the first ovum produced after a single insemination of $100 \times 10^{\prime \prime}$ spermatozoa in domestic fowl may have as many as 99000 spermatozoa on the outer perivitelline layer. Successive eggs had fewer spermatozoa, and when the number of spermatozoa fell to 206 the probability of an egg being fertile was $50 \%$. The equivalent value for zebra finches was 20 spermatozoa. It is possible to compare the two species by calculating the number of spermatozoa relative to the surface area of the respective ova. Wishart (1987) reported a surface area of $2828 \mathrm{~mm}^{2}$ for domestic fowl ova, which gives a ratio of spermatozoa to surface area of 0.073 . The ratio for zebra finches was 0.088 from an ovum surface area of $226 \mathrm{~mm}^{2}$. Therefore, there was no evidence that the larger ova of domestic fowl required relatively more spermatozoa to ensure a $50 \%$ probability of fertilization. However, in contrast to zebra finches, domestic fowl have been under strong artificial selection for fertility for many generations.

One of the critical assumptions of previous studies on the outcome of sperm competition in zebra finches was that the rate of loss of spermatozoa from the female tract does not differ significantly for females inseminated before and after the onset of laying (Birkhead et al., 1988; Colegrave et al., 1995). The results of the present study are in agreement with this assumption. However, it is possible that the rate of loss of spermatozoa was not the same, if either ejaculate size or the proportion of spermatozoa retained by the sperm storage tubules varied between the two time periods in a way that was exactly compensatory. In turkeys, the relative number of spermatozoa taken up by the sperm storage tubules after artificial insemination is greater for inseminations made before compared with during egg laying (Brillard and Bakst, 1990). However, it is not known whether the rate of loss from the tubules differs between inseminations made before or after egg laying. In the present study, there was no evidence that the uptake of spermatozoa was greater for inseminations made before laying, since there was no difference in the intercepts relative to the time of insemination. However, this possibility cannot be excluded completely.

Birkhead of al. (1993b) reported that the instantaneous per capita rate of loss of spermatozoa was $0.026 \pm 0.007(n=5$ clutches, each from a different female). In the present study the mean of the mean values for each of the seven females used to investigate repeatability was $0.0170 \pm 0.0016$, and the values obtained from females inseminated before and after the onset of egg laying were $0.01445 \pm 0.0028$ and $0.0167 \pm$ 0.002 , respectively. These values are all lower than that reported by Birkhead et al. (1993b), partly because of the relatively large variance and the small sample size of the earlier study. The variability in the rate of loss of spermatozoa from the female finch tract indicates that the $95 \%$ confidence interval for an accuracy of 0.005 requires a sample size of about 25 females. A sample of 32 females and an estimate of $0.0170 \pm 0.002$ is achieved by pooling data from the present study and that of Birkhead et al. (1993b) and using the values from each female only once at random. This value lies within the $95 \%$ confidence limits of the experimental estimates (N. Colegrave, personal communication), thus the conclusions from the earlier study are still valid. However, the fit between the predicted and observed outcomes in the sperm competition model (Colegrave it al., 1995) is less good than was previously reported (Birkhead it al. 1993b).

The results indicate that in some females spermatozoa move through the infundibulum more slowly than they move from the sperm storage tubules to the infundibulum. The consequence of this is that spermatozoa tend to accumulate in the infundibulum. However, the rate at which spermatozoa move through the infundibulum is not known, nor are there any equivalent data for other bird species.

In conclusion, the rate at which spermatozoa are released from the sperm storage tubules in separate clutches is not consistent in individual female zebra finches. In addition, the results of this study confirm that the rate of loss of spermatozoa does not differ between inseminations occurring before or after the onset of egg laying.

The authors thank J. D. Biggins, N. Colegrave, C. M. Lessells and G. J. Wishart for useful comments on the manuscript. The research 
was funded by grants to T. R. Birkhead from BBSRC and The Royal Society.

\section{References}

Bakst MR and Howarth BJ (1977) Hydrolysis of the hen's perivitelline laver by cock sperm in itro. Biology of Reproduction 17 370-379

Bakst MR, Wishart GJ and Brillard JP (1944) Oviductal sperm selection, transport and storage in poultry Poultry Science Re'iciw 5 117-143

Bedford MJ (1970) The saga of mammalian sperm from ejaculation to syngamy. In Mammalian Reproduction pp 124-182 Eds H Gibian and FJ Plotz. Springer-Verlag, Berlin

Birkhead TR (1996) Sperm competition: evolution and mechanisms Current Topics in Dezelopmenthal Biology 33 103-158

Birkhead TR and Moller AP (1992) Sperm Comprtition in Birds: Eivolutionury Couse's ath Conserpue'nce's Academic Press, London

Birkhead TR and Moller AP (1996) Monogamy and sperm competition in birds. In Partherships in Birds: the Ecology of Monogamy pp 323-343 Ed. JM Black. Oxford University P'ress, Oxford

Birkhead TR and Parker GA (1997) Sperm competition and mating systems. In Brhavioural Ecology: An Euolutionary Approath pp 121-145 Eds JR Kreband and NB Davies. Blackwell, Oxford

Birkhead TR and Moller AP (1998) Sperm Competition and Sexul silection Acodemic Press, London

Birkhead TR and Biggins JD (1998) Sperm competition mechanisms in birds: models and data Behtowionral Ecology 9 253-260

Birkhead TR, Atkin L and Moller AP (1987) Copulation behaviour of birds Behowiour 101 101-138

Birkhead TR, Pellatt JE and Hunter FM (1988) Extra-pair copulation and sperm competition in the zebra finch Nature (London) 334 60-62

Birkhead TR, Hunter FM and Pellatt JE (T989) Sperm competition in the zebra finch, Tneniopuging guttati. Animal Behariour 38 935-950

Birkhead TR, Meller AP and Sutherland WJ (1993a) Why do females make it so difficult for males to fertilize their eggrs? fournal of Theoretical Biology 161 $51-60$

Birkhead TR, Pellatt EJ and Fletcher F (1993b) Selection and utilization of spermatozoa in the repreductive tract of the female zebra finch Tieniopugin guttatio. Journal of Reproutuction and Fertility 99593-600

Birkhead TR, Sheldon BC and Fletcher F (1994) A comparative study of sperm-egg interactions in birds fournal of Reproduction and Fertility 101 353-361

Birkhead TR, Fletcher F, Pellatt EJ and Staples A (1995) Ejaculate quality and the success of extra-pair copulations in the zebra finch Nature (lomdon) 377 $422-423$

Bobr LW, Ogasawara FX and Lorenz FW (1964) Distribution of spermatozoa in the oviduct and fertility in domestic birds. II. Transport of spermatozoa in the fowl oviduct Joumal of Reprotuction and Fertility $849-58$

Brillard JP (1990) Migration of spermatozoa in the oviduct of hens following intravaginal, intramagnal and intra-abdominal insemination Theriogenology $331021-1029$

Brillard JP (1993) Sperm storage and transport following natural mating and artificial insemination $P_{0 u l t r y}$ Scichce 72923928

Brillard JP and Antoine $\mathbf{H}$ (1990) Storage of sperm in the uterovaginal junction and its incidence on the numbers of spermatozoa present in the perivitelline layer of hens' eggs British Poultry Scince 31 635-644

Brillard JP and Bakst MR (1990) Quantification of spermatozoa in the sperm storage tubules of turkey hens and its relation to sperm numbers in the perivitelline layer of eggs Biology of Reproduction $43271-275$

Colegrave N, Birkhead TR and Lessells CM (1995) Sperm precedence in zebra finches does not require special mechanisms of sperm competition Procitings of the Royal Socinty Lomiton Series B 259 223-228

Drobnis EZ and Overstreet JW (1992) Natural history of mammalian spermatozoa in the female reproductive tract Oxford Recieas of Reproduction Biology 14 1-45

Haywood S (1993) Sensory control of clutch size in the zebra finch Tatniopy/sia guituta. AUK $110778-786$

Kosin IL (1945) The accuracy of the macroscopic method in identifying fertile unincubated germ discs Poultry Sciences 24 281-283

Lessells CM and Boag PT (1987) Unrepeatable repeatabilities: a common mistake ALIK 104 116-121

Lessells CM and Birkhead TR (1990) Mechanisms of sperm competition in birds: mathematical models Belinoioural Ecology and Sociohiology 27 325-3.37

Parker GA (1970) Sperm competition and its evolutionary consequences in the insects Biological Reviews 45 525-567

Smith RL (1984) Sperm Competition and the Ezolution of Animal Mating Systems Academic Press, Orlando

Steele MG, Meldrum W, Brillard JP and Wishart GJ (1994) The interaction of avian spermatozoa with the perivitelline laver in vitro and in wizo. Yournal of Reproduction and Fertility 101 599-603

Suarez SS, Drost M, Redfern K and Gottlieb W (1990) Sperm motility in the oviduct. In Fertilization in Mammals pp 111-124 Eds BD Bavister, J Cummins and ERS Roldan. Serono Symposia, Norwell, MA

Wishart GJ (1987) Regulation of the length of the fertile period in the domestic fowl by numbers of oviductal spermatozoa as reflected by those trapped in laid eggs fournal of Reproduction and Fertility $80493-498$

Wishart GJ (1995) New approaches to evaluating male and female fertility. In Proceddings of the First Intermational Symposinn on the Artificial Insemination of Poultry Pp 207-223 Eds MR Bakst and GJ Wishart. The Poultry Science Association Inc., Illinois

Zann RA (1996) The Zebra Finch: A Synthesis of Fild and Laboratory Studies Oxford University Press, ()xford 